\title{
An Influence of the Synthesis Conditions on the PFN Ceramics Properties
}

\author{
D. BOCHENEK* AND Z. SUROWIAK
}

Department of Materials Science, University of Silesia, Śnieżna 2, 41-200 Sosnowiec, Poland

In the work tests of the influence of the technological conditions on the basic applied properties of the $\mathrm{Pb}\left(\mathrm{Fe}_{0.5} \mathrm{Nb}_{0.5}\right) \mathrm{O}_{3}$ ceramics were carried out. The $\mathrm{Pb}\left(\mathrm{Fe}_{0.5} \mathrm{Nb}_{0.5}\right) \mathrm{O}_{3}$ specimens were obtained by a two-stage method of synthesizing (the niobite method), a technique of the powder mixture calcinations, changing a temperature range of the iron-niobate $\left(\mathrm{FeNbO}_{4}\right)$, whereas compacting was conducted by free sintering.

PACS numbers: 77.80.-e, 68.37.Hk, 77.80.Bh, 77.22.Gm

\section{Introduction}

Progress in the modern piezoelectronics is conditioned by achievements in technology and investigations of new ferroelectric and ferroelectromagnetic ceramic materials to a great extent. They should be characterized not only by good electromagnetic physical parameters but high stability of their parameters in time at temperature as well. A set of applied parameters deciding about usability of the $\mathrm{Pb}\left(\mathrm{Fe}_{0.5} \mathrm{Nb}_{0.5} \mathrm{O}_{3}(\mathrm{PFN})\right.$ type ceramics to construct piezoelectric transducers depends on its chemical composition and production conditions, which have a significant influence on the ceramic domain structure. Quality and stability of the ceramic domain structure of a piezoelectric in the working temperature range is connected closely with working parameters of given equipment. An increase in requirements which those materials are to meet makes that in spite of many years of experience works are still being conducted on improving technologies of that type of the ceramics.

The PFN belonging to a group of biferroics shows both ferroelectric and antiferromagnetic properties at the specified temperature ranges. Those types of materials, called ferroelectromagnetics are used widely as multi-state memory elements, electrically controlled ferromagnetic resonant systems, namely transducers with magnetically modulated piezoelectricity, mainly in a form of volumetric or thin layer ceramic elements. The PFN ceramics has a structure of a perovskite type with $\mathrm{A}\left(\mathrm{B}^{\prime} \mathrm{B}^{\prime \prime}\right) \mathrm{O}_{3}$ general formula. In that material a big lead ion substitutes itself into position $\mathrm{A}$, whereas in octahedral positions $\mathrm{B}^{\prime}$ and $\mathrm{B}^{\prime \prime}$, iron and niobium ions substitute themselves in a random way [1-3]. This material can be used as a dielectric and magnetic medium as well as for multilayer ceramic capacitors (MLCC) and inductors, multi-

\footnotetext{
* corresponding author; e-mail: dbochene@us.edu.pl
}

layer microwave resonators and filters as tunable transducers, pyroelectric sensors, electrostrictive actuators, micropositiometers and memory devices [3-8]. The recent investigations have shown that in majority of cases a fine-grained ceramic with high degree of homogeneity and density is required.

An aim of this work was to develop a technology of making the PFN ceramics with the best applied parameters being a base for a material suitable to be used in piezoelectronics. Improvement of the technological process aimed at, first of all, increasing density (decreasing porosity), increasing chemical and physical homogeneity, improving stoichiometry of the chemical composition (including reducing of $\mathrm{Pb}$ losses), decreasing grain sizes and decreasing electric conduction, to obtain a ceramics without undesired pyrochlore phase.

\section{Experiment}

The PFN ceramics specimens were obtained by the columbite method (a two-stage synthesis of powders). In the first stage the $\mathrm{FeNbO}_{4}$ iron-niobate was obtained from a mixture of the $\mathrm{Fe}_{2} \mathrm{O}_{3}$ and $\mathrm{Nb}_{2} \mathrm{O}_{5}$ oxides, whereas in the second stage by adding the $\mathrm{PbO}$ lead oxide to powdered $\mathrm{FeNbO}_{4}$ a final product was obtained in a form of the PFN powder. The mixture of the $\mathrm{Fe}_{2} \mathrm{O}_{3}$ and $\mathrm{Nb}_{2} \mathrm{O}_{5}$ oxides was synthesized at different temperatures: $1000^{\circ} \mathrm{C}, 1050^{\circ} \mathrm{C}, 1100^{\circ} \mathrm{C}$ and $1150^{\circ} \mathrm{C}$ for $4 \mathrm{~h}$. The optimum conditions of a synthesis of the $\mathrm{FeNbO}_{4}$ and $\mathrm{PbO}$ mixture turned out to be $T=800^{\circ} \mathrm{C}$ and $t=3 \mathrm{~h}$. Compacting of powders was made by the free sintering (FS) $\operatorname{method}\left(T_{\mathrm{s}}=1050^{\circ} \mathrm{C} / t_{\mathrm{s}}=2 \mathrm{~h}\right)$.

The X-ray measurements were conducted on a polycrystalline diffractometer of the Phillips firm with a $\mathrm{Cu}$ lamp and a graphite monochromator. The microstructure examinations for the obtained PFN ceramics specimens were performed by a SEM microscope scanning with field emission, HITACHI S-4700. Temperature di- 
electric measurements were made on a capacity bridge of a QuadTech 1920 Precision LCR Meter type, with a heating rate of $0.5^{\circ} / \mathrm{min}$ for a heating cycle. Real density was determined by measurements of the specimen mass and volume, and $\rho_{\text {theor }}=8.457 \mathrm{~g} / \mathrm{cm}^{3}$ was taken as the X-ray density $[9,10]$. Percentage content of the $P_{\mathrm{f}}$ perovskite phase was calculated from the following relationship:

$$
P_{\mathrm{f}}=\frac{I_{110} \cdot 100}{I_{110}+I_{222}}[\%]
$$

where $I_{110}$ and $I_{222}$ are intensities of the (110) perovskite and (222) pyrochlore diffraction lines.

\section{Test results and their discussion}

The technology by a two-stage synthesis method through the powder calcination enables to obtain a final product in a form of the PFN ceramics with high density close to the theoretical one (Table) and with a microstructure with a fine and densely packed grain (Fig. 1). Specimen N-1 of the lowest temperature of the $\mathrm{FeNbO}_{4}$ synthesis shows the greatest grain homogeneity (Fig. 1a), whereas at higher temperature of the iron-nioban synthesis specimens have bigger and non-uniform grains and they are characterised by cracking through the grain (Fig. 1d). X-ray photographs of the tested specimens are presented in Fig. 2. It can be seen that in specimens $\mathrm{N}-1$ and $\mathrm{N}-2$ there is no undesired pyrochlore phase, whereas the pyrochlore phase appears in specimens $\mathrm{N}-3$ and N-4.
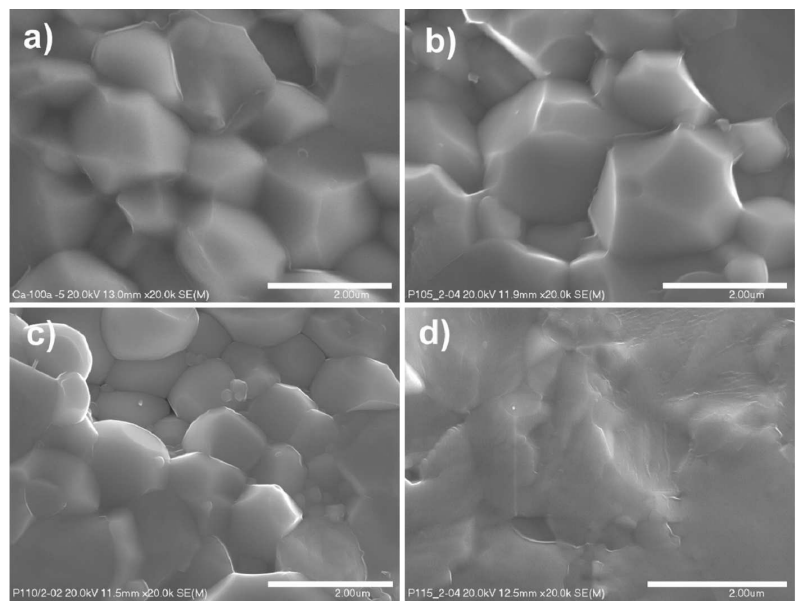

Fig. 1. SEM photographs of the microstructure fracture of the PFN ceramics specimens: (a) $\mathrm{N}-1$, (b) $\mathrm{N}-2$, (c) N-3, (d) N-4 (×20000).

Temperature relationships of permittivity of the PFN ceramics at $1 \mathrm{kHz}$ frequency are presented in Fig. 3. An increase in the iron-niobate $\left(\mathrm{FeNbO}_{4}\right)$ synthesis temperature causes an increase in the Curie temperature at slight differences of the maximum permittivity values (Table).
The iron-niobate synthesis temperature has an influence on dielectric loss values of the PFN ceramics (Fig. 3). An increase in the $\mathrm{FeNbO}_{4}$ synthesis temperature causes an increase in dielectric losses. Analysing the $\tan \delta(T)$ diagrams, it can be seen that with an increase in the temperature in the ferroelectric phase the dielectric losses increase slowly, whereas above the phase transition temperature (in the paraelectric phase), there is their rapid increase. It is connected both with a decrease in electric resistance of the grains themselves and grain boundaries (a temperature effect of the synthesis connected with irreversible chemical changes on the grain boundaries during sintering at high temperatures).

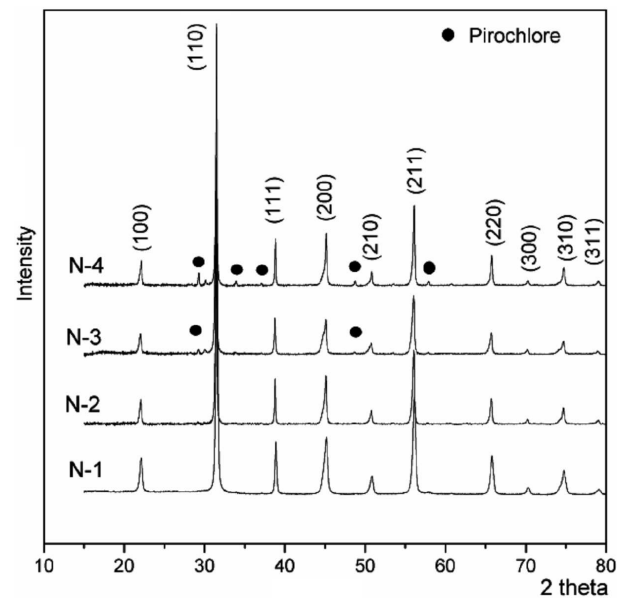

Fig. 2. X-ray spectra of the PFN ceramics of a different temperature of the $\mathrm{FeNbO}_{4}$ synthesis.

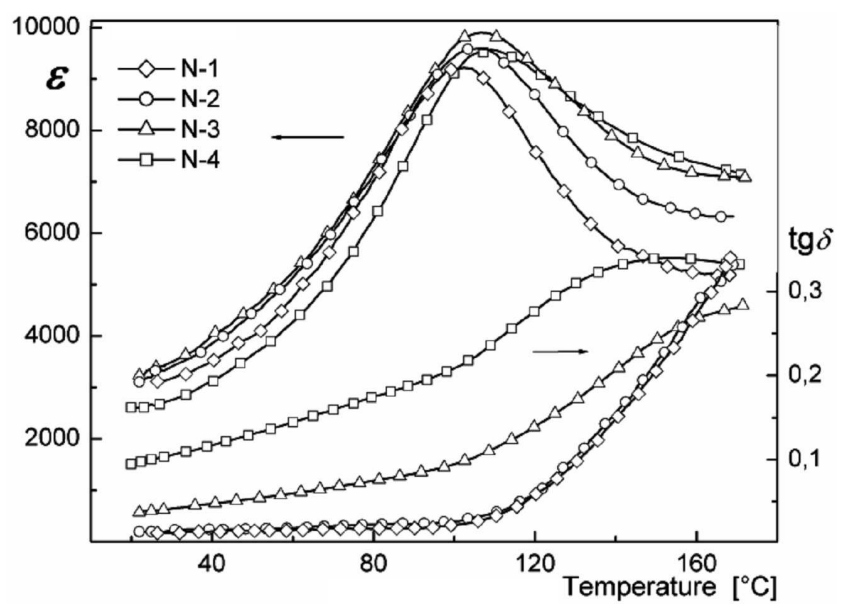

Fig. 3. Relationships of the permittivity $\varepsilon$ and the tangent of dielectric losses $\tan \delta$ in the temperature function for the PFN ceramics obtained in different conditions of the $\mathrm{FeNbO}_{4}$ synthesis. 
TABLE

Parameters of the PFN ceramics (heating cycle).

\begin{tabular}{c|c|c|c|c|c|c|c|c|c}
\hline \hline Sign & $\begin{array}{c}\text { Sintering } \\
\mathrm{FeNbO}_{4}\end{array}$ & $\begin{array}{c}\rho_{\exp } \\
{\left[\mathrm{g} / \mathrm{cm}^{3}\right]}\end{array}$ & $\begin{array}{c}\rho_{\exp } / \rho_{\text {theor }} \\
\times 100[\%]\end{array}$ & $\begin{array}{c}P_{\mathrm{f}} \\
{[\%]}\end{array}$ & $\begin{array}{c}T_{\mathrm{m}} \\
{\left[{ }^{\circ} \mathrm{C}\right]}\end{array}$ & $\varepsilon_{\mathrm{r}}$ & $(\tan \delta)_{\operatorname{Tr}}$ & $\varepsilon_{\mathrm{m}}$ & $(\tan \delta)_{\mathrm{Tm}}$ \\
\hline $\mathrm{N}-1$ & $1000^{\circ} \mathrm{C} / 4 \mathrm{~h}$ & 8.19 & 96.9 & 100 & 102 & 2960 & 0.013 & 9230 & 0.023 \\
$\mathrm{~N}-2$ & $1050^{\circ} \mathrm{C} / 4 \mathrm{~h}$ & 8.12 & 96.0 & 100 & 105 & 3070 & 0.014 & 9590 & 0.029 \\
$\mathrm{~N}-3$ & $1100^{\circ} \mathrm{C} / 4 \mathrm{~h}$ & 7.45 & 88.1 & 97.3 & 107 & 3090 & 0.036 & 9900 & 0.107 \\
$\mathrm{~N}-4$ & $1150^{\circ} \mathrm{C} / 4 \mathrm{~h}$ & 6.68 & 79.0 & 95.6 & 109 & 2590 & 0.096 & 9570 & 0.234
\end{tabular}

The highest dielectric losses show the specimens with a temperature of the first synthesis of $T=1150^{\circ} \mathrm{C}(\mathrm{N}-4)$, whereas the lowest ones specimens with the lowest temperature of the first synthesis of $T=1000^{\circ} \mathrm{C}(\mathrm{N}-1)$.

Looking for compromise between obtaining the PFN with high values of permittivity on one hand, and a material with the lowest dielectric losses on the other, it can be stated that the optimum temperature of the $\mathrm{FeNbO}_{4}$ sintering in time $t_{\mathrm{s}}=4 \mathrm{~h}$ is $T_{\mathrm{s}}=1000^{\circ} \mathrm{C}$ temperature.

\section{Conclusions}

Applied parameters and the PFN ceramics properties depend mainly on its crystalline structure and microstructure. A way, method and accuracy of the conducted technological process have an influence on a degree of excellence of the crystalline structure and microstructure.

High dielectric losses and possibility of non-perovskite pyrochlore phase, formed during the $\mathrm{Pb}\left(\mathrm{Fe}_{0.5} \mathrm{Nb}_{0.5}\right) \mathrm{O}_{3}$ ceramics production limit application possibilities of those materials. In the work a technology, in which a single phase PFN ceramics is obtained, was developed. PFN technology process reducing greatly unfavorable factors, at use of specific technological conditions and accuracy of the process performed, was conducted by the two-stage columbite method, using synthesizing by the powder calcinations.

The dielectric losses of the PFN ceramics increase with an increase in the iron-niobate $\left(\mathrm{FeNbO}_{4}\right)$ synthesis temperature. Use of powder sintering in the PFN ceramics technology, namely a method of non-compact synthesizing, different temperatures of the iron-niobate synthesiz- ing showed that for time $4 \mathrm{~h}$ the optimum temperature to obtain the PFN ceramics with the best applied properties, with high values of permittivity and low dielectric losses, is $1000^{\circ} \mathrm{C}$.

\section{Acknowledgments}

This work was realized within a framework of research project N507 142 31/3568 financed by the Polish Ministry of Science and Higher Education.

\section{References}

[1] D. Bochenek, P. Wawrzała, Arch. Acoust. 31, 513 (2006).

[2] T. Pustelny, A. Opilski, B. Pustelny, Acta Phys. Pol. A 114, A-183 (2008).

[3] V.V. Bhat, K.V. Ramanujachary, S.E. Lofand, A.M. Umarji, J. Magn. Magn. Mater. 280, 221 (2004).

[4] X. Gao, J. Xue, J. Wang, J. Am. Ceram. Soc. 85, 565 (2002).

[5] O. Raymond, R. Font, N. Suarez, J. Portalles, J.M. Siqueiros, Ferroelectrics 294, 141 (2003).

[6] T. Pustelny, B. Pustelny, Europ. Phys. J. - Special Topics 154, 265 (2008).

[7] K. Singh, S.A. Band, W.K. Kinge, Ferroelectrics 306, 179 (2004).

[8] J.T. Wang, C. Zhang, Z.X. Shen, Y. Feng, Ceram. Inter. 30, 1627 (2004).

[9] J. Bartkowska, J. Ilczuk, Acta Phys. Pol. A 114, A-7 (2008).

[10] S. Ananta, N.W. Thomas, J. Europ. Ceram. Soc. 19, 1873 (1999). 